\title{
Study on the Correlation among Sleep Quality, Cognitive Function, and Self-Management Ability in Hospitalized Elderly Patients with Coronary Heart Disease
}

\author{
Zhoumin Shen, ${ }^{1}$ Huali Chen, ${ }^{1}$ Yimin Cai ${ }^{1},{ }^{1}$ Bifang Zhou, ${ }^{1}$ Hongjiao Chen, ${ }^{2}$ and Nian Xie ${ }^{2}$ \\ ${ }^{1}$ Nursing Department, Hunan Provincial People's Hospital, Changsha, Hunan 410013, China \\ ${ }^{2}$ Department of Nursing, Hunan Normal University School, Changsha, Hunan 410013, China \\ Correspondence should be addressed to Yimin Cai; 158460107@qq.com
}

Received 9 July 2021; Accepted 20 July 2021; Published 3 August 2021

Academic Editor: Songwen Tan

Copyright ( 2021 Zhoumin Shen et al. This is an open access article distributed under the Creative Commons Attribution License, which permits unrestricted use, distribution, and reproduction in any medium, provided the original work is properly cited.

\begin{abstract}
Background. Coronary heart disease (CHD) is the leading cause of death worldwide. The incidence of cardiovascular disease is especially common in low-level and middle-income countries. With the increase in the number of patients with CHD and the complexity of treatment on patients with $\mathrm{CHD}$, many hospitals are devoted to developing new models of care and management for patients with CHD. Understanding the unique characteristics of the patient's condition, including factors related to selfmanagement, cognitive function, and sleep quality, will lead to a substantial reduction in cardiovascular disease and related mortality. Objective. To investigate the correlation among sleep quality, cognitive function, and self-management ability in hospitalized elderly patients with coronary heart disease (CHD). Methods. 120 hospitalized elderly patients with coronary heart disease (CHD) were investigated by using a self-designed general data questionnaire, Pittsburgh Sleep Quality Index (PSQI), Montreal Cognitive Function Assessment (MoCA) scale, and Coronary Heart Disease Self-management Behavior Scale (CSMS). Results. The Spearman analysis showed that sleep quality was positively correlated with cognitive function in hospitalized elderly CHD patients $(P<0.05)$. Sleep quality was positively correlated with self-management ability in CHD patients $(P<0.05)$. Conclusion. Improving the cognitive function and self-management ability of elderly patients with coronary heart disease can improve their sleep quality.
\end{abstract}

\section{Introduction}

Coronary heart disease (CHD) is the main cause of high morbidity and mortality, leading to immense health and economic burden globally, which concludes hypertension, atherosclerosis, cardiomyopathy, and heart failure [1]. With the aging of the population, $\mathrm{CHD}$ has become the most common cause of death from noncommunicable diseases, accounting for more than $40 \%$ of residents' death from disease $[2,3]$. CHD is a global burden unmatched by any other noncommunicable disease. Approximately 26 million patients are diagnosed with heart failure, and over 39 billion dollars is spent annually in heart failure-related treatments [4]. Common pathological processes and risk factors include inflammation, dyslipidemia, and diabetes; meanwhile, all of these risk factors will affect the initiation and progression of
CHD $[5,6]$. Moreover, some other risk factors like insulin resistance, obesity, and unhealthy lifestyle such as lack of exercise, poor dietary habits, and smoking have relevance to CHD [7]. However, all the consequences of CHD cannot be fully explained by the risk factors mentioned above.

Recently, a study on the correlation among sleep quality, cognitive function, and self-management ability in hospitalized elderly patients with coronary heart disease has been increasingly favored by researchers. At present, the treatment of coronary heart disease mainly included drug therapy, percutaneous coronary intervention (PCI), lipid-lowering therapy, external counterpulsation therapy (EECP), and a comprehensive treatment containing various treatment methods $[8,9]$. Although great improvement of the patients' prognosis can be achieved through treatment methods, various treatment methods and the disease itself have different 
impacts on the sleep quality, cognitive function, and selfmanagement ability of hospitalized elderly patients with coronary heart disease [10].

This study intends to explore the correlation among sleep quality, cognitive function, and self-management ability of hospitalized elderly patients with $\mathrm{CHD}$, so as to provide a theoretical basis for further research in the future.

\section{Object and Method}

2.1. Survey Object. The objects of this study were from two tertiary first-class hospitals in Changsha city, Hunan province, from December 2017 to August 2018. In this study, a target sampling method was adopted to select 120 patients in hospitalized elderly patients with CHD.

Inclusion criteria are as follows: (1) age is $\geq 60$ years old, (2) the patients diagnosed with ischemic heart disease in an electrocardiogram (ECG) test or had a positive result of coronary angiography, and (3) all participants voluntarily agreed to participate in this study and all provided written informed consent.

Exclusion criteria are as follows: (1) patients in critical condition, had severe cardiopulmonary insufficiency, and with abnormal liver and kidney function; (2) patients with a history of mental illness or had severe cognitive impairment; (3) patients who have language communication barriers and cannot communicate normally with others. This study has been reviewed and approved by the ethics committee of our hospital.

2.2. Survey Method. The questionnaires in this study include a self-designed general information questionnaire, Pittsburgh Sleep Quality Index (PSQI), Montreal Cognitive Function Assessment (MoCA) scale, and Coronary Heart Disease Self-Management Behavior Scale (CSMS).

2.2.1. Preparation Stage for Data Collection. In the start of the experimental design, researchers extensively studied many documents including online books and offline books, as well as the literatures related to this topic. And then, the reasonable modifications of the experimental plan were made after being reviewed by experts. Finally, the experimental plan of this study was proposed.

2.2.2. Data Collection Stage. All data were collected with the permission of relevant departments and the nursing supervisor. After patiently communicating with the research objects and obtaining their consent, the questionnaires were distributed to the objects. When all questionnaires were finished, a researcher will check the accuracy and completeness of the filled questionnaires. If there are any omissions or errors, the research objects will be asked to make a supplement for the omissions and make modification for the errors. At the same time, certain key indicators will be verified again with the research objects to ensure the authenticity of all collected data. All data were collected by the designated investigator, so as to reduce the selection bias from different investigators.

2.2.3. Data Processing and Analysis Stage. All data will be checked again, and the data that do not meet the requirement will be deleted. After that, we used the SPSS 21.0 software to statistically analyze and evaluate all collected data. Descriptive statistical analysis methods such as analysis of variance, chi-square test, and Spearman's analysis were mainly adopted in this work.

\section{Result}

3.1. Chi-Square Test of Sleep Status of Hospitalized Elderly with CHD. In this study, 120 questionnaires were distributed to the elderly patients with CHD. After completing the questionnaire survey, 120 valid questionnaires were received with an effective recovery rate of $100 \%$. Among them, 66 patients are male and 54 patients are female. All patients that participated in this study are aged between 60 and 85. According to the PSQI standard, we divided the patient's sleep status into two groups, which are the normal sleep group and sleep disorder group. In the sleep quality assessment of all volunteers, the PSQI score of 7 was set as a boundary value. All volunteers were grouped according to the difference of demographic and past history of patients. The statistical significance will be assessed by comparing the differences in the incidence of patients with sleep disorder. The chi-square test of sleep status of all hospitalized elderly patients with CHD is summarized in Table 1 . We found that there were 27 volunteers who had a total PSQI score over 7 in this study through data analysis of Table 1.

\subsection{The Correlation among Sleep Quality, Cognitive Function, and Self-Management Ability in Patients with CHD}

3.2.1. Study and Analysis of the Correlation between Sleep Quality and Cognitive Function in Patients with CHD. Poor sleep quality can predict adverse outcomes in patients with CHD [11-14]. A comprehensive understanding of the risk factors of poor sleep quality can help us take reasonable measures to reduce the risk of poor sleep quality, which may reduce the incidence and mortality of patients with $\mathrm{CHD}$. Known demographic risk factors for sleep quality include age, gender, education, income, and marriage status [1517]. The poor sleep quality is a very common issue in an older person. As so far, $50 \%$ of elderly people are suffering from severe sleep issue $[18,19]$. Studies have found that the quality of sleep in the elderly has an important correlation with cognitive ability [20]. Therefore, in this study, we tried to use a statistical investigation method to study the correlation between sleep quality and cognitive ability in an elderly patient with $\mathrm{CHD}$.

We performed the PSOI and MoCA normality test on all data. The results of the PSOI and MoCA normality test showed that all data collected from the total score or scores of each dimension did not obey the normal distribution. Thus, the Spearman method was used for correlation analysis. We discussed the statistical significance of the results and found that there was a negative correlation between the total score of PSOI and the total score of MoCA in Table 2. The values of negative correlation and coefficient were $P<$ 0.05 and -0.112 , respectively. In addition, the patients that 
TABLE 1: Chi-square test of sleep status of hospitalized elderly with CHD.

\begin{tabular}{|c|c|c|c|c|c|c|}
\hline Variable & Grouping & $\begin{array}{c}\text { Normal sleep } \\
\text { group }\end{array}$ & $\begin{array}{l}\text { Sleep disorder } \\
\text { group }\end{array}$ & $\begin{array}{c}\text { Total } \\
\text { number }\end{array}$ & $\begin{array}{c}\text { Chi-square } \\
\text { value }\end{array}$ & $\begin{array}{c}P \\
\text { value }\end{array}$ \\
\hline \multirow{6}{*}{ Age } & \multirow{2}{*}{$60-70$} & 47 & 13 & \multirow{2}{*}{60} & \multirow{2}{*}{4.793} & \multirow{2}{*}{0.091} \\
\hline & & 78.33 & 21.67 & & & \\
\hline & \multirow{2}{*}{$70-80$} & 39 & 9 & \multirow{2}{*}{48} & & \\
\hline & & 81.25 & 18.75 & & & \\
\hline & \multirow{2}{*}{$\geq 81$} & 8 & 4 & \multirow{2}{*}{12} & & \\
\hline & & 66.67 & 33.33 & & & \\
\hline \multirow{4}{*}{ Gender } & \multirow{2}{*}{ Male } & 52 & 14 & \multirow{2}{*}{66} & \multirow{4}{*}{3.268} & \multirow{4}{*}{0.071} \\
\hline & & 78.79 & 21.21 & & & \\
\hline & \multirow{2}{*}{ Female } & 42 & 12 & \multirow{2}{*}{54} & & \\
\hline & & 77.78 & 22.22 & & & \\
\hline \multirow{4}{*}{ Living situation } & \multirow{2}{*}{ Cohabitation } & 85 & 25 & \multirow{2}{*}{110} & \multirow{4}{*}{3.778} & \multirow{4}{*}{0.052} \\
\hline & & 77.27 & 22.73 & & & \\
\hline & \multirow{2}{*}{ Live alone } & 10 & 0 & 10 & & \\
\hline & & 100 & 0 & 10 & & \\
\hline & Uneducated & 6 & 2 & 8 & 2563 & 0633 \\
\hline & . Sileducaled & 75 & 25 & 8 & 2.563 & 0.035 \\
\hline & Primary education & 30 & 6 & 26 & & \\
\hline & Primary eaucation & 83.33 & 16.67 & 36 & & \\
\hline Educational level & Secondary education & 35 & 5 & 40 & & \\
\hline Lutucalional ievel & secondary equedion & 87.5 & 12.5 & 40 & & \\
\hline & High school education/technical & 23 & 4 & 27 & & \\
\hline & secondary education & 85.19 & 14.81 & 27 & & \\
\hline & University education & 7 & 2 & 9 & & \\
\hline & University education & 77.78 & 22.22 & 9 & & \\
\hline & Married & 86 & 26 & 112 & 3007 & 0220 \\
\hline & Niantied & 76.79 & 23.21 & 112 & 0.007 & 0.222 \\
\hline Marriage & Divorce & 2 & 0 & 2 & & \\
\hline Nivilitage & Divorce & 100 & 0 & 2 & & \\
\hline & Widowed & 6 & 0 & 6 & & \\
\hline & Widowed & 100 & 0 & 6 & & \\
\hline & $<1000$ & 18 & 3 & 21 & 6312 & 0097 \\
\hline & $\leq 1000$ & 85.71 & 14.29 & 21 & 0.312 & 0.097 \\
\hline & $1000 \sim 3000$ & 37 & 14 & 51 & & \\
\hline Monthly earning & $1000 \sim 5000$ & 72.55 & 27.45 & 31 & & \\
\hline Noontiny eaniming & 3001,5000 & 29 & 7 & 36 & & \\
\hline & $3001 \sim 5000$ & 80.56 & 19.44 & 36 & & \\
\hline & $>5000$ & 10 & 2 & 12 & & \\
\hline & $>5000$ & 83.33 & 16.67 & 12 & & \\
\hline & Provincial medical incurance & 25 & 9 & & & \\
\hline & Provincial medical insurance & 73.53 & 26.47 & 34 & 2.219 & 0.528 \\
\hline & Municinal medical insurance & 37 & 9 & 46 & & \\
\hline Payment method of medical & Municipal medical insurance & 80.43 & 19.57 & 46 & & \\
\hline expenses & New rural cooperative medical & 30 & 8 & 20 & & \\
\hline & insurance & 78.95 & 21.05 & 38 & & \\
\hline & & 2 & 0 & & & \\
\hline & Selt-pay & 100 & 0 & 2 & & \\
\hline
\end{tabular}


TABLe 1: Continued.

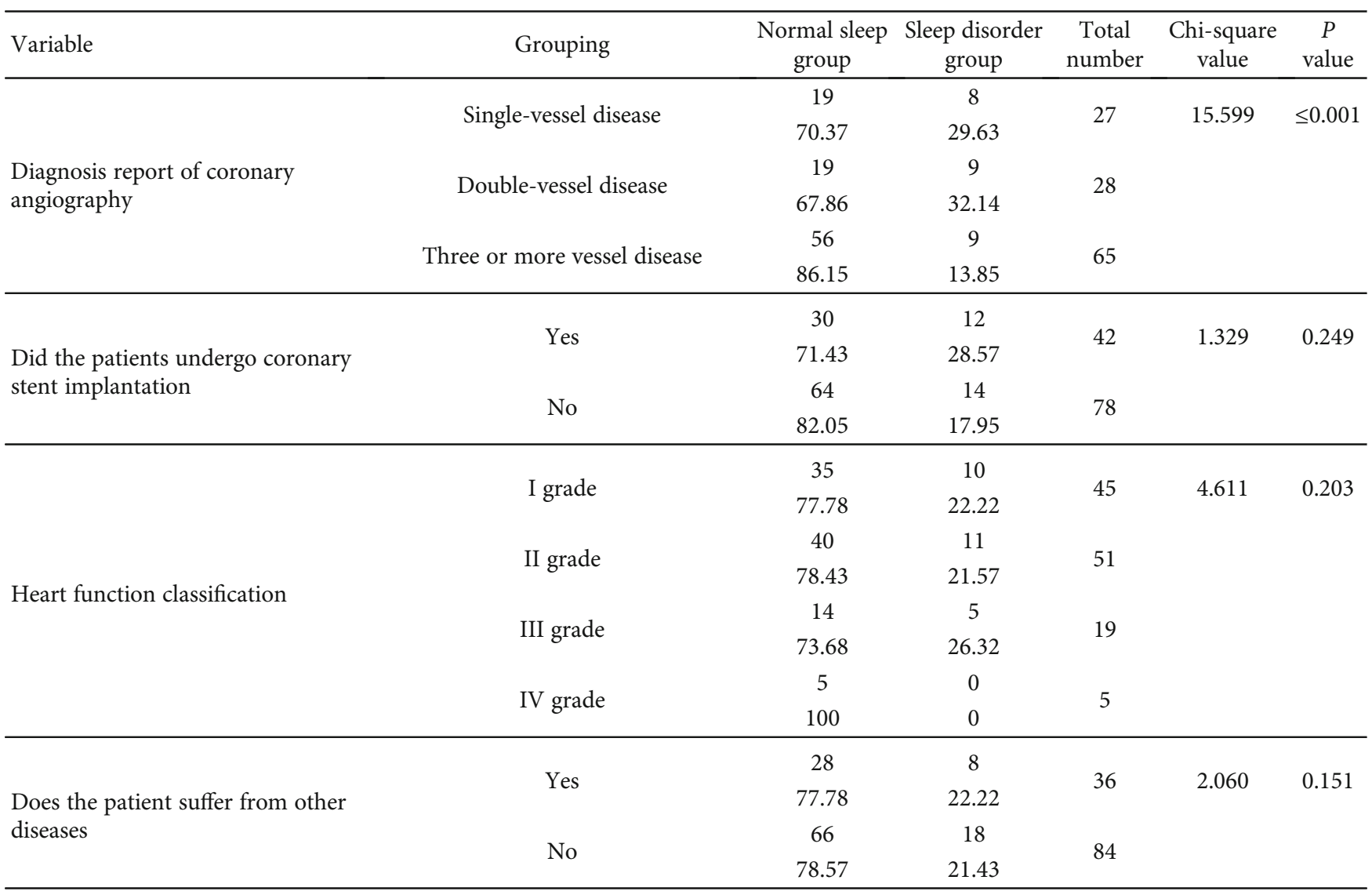

had a higher value of total score of PSOI had poorer sleep quality from the results of Table 2 .

3.2.2. Study and Analysis of the Correlation between Sleep Quality and Self-Management Ability in Patients with CHD. Many recommended therapies for CHD including revascularization by coronary artery bypass graft or percutaneous coronary intervention are significantly efficacious in reducing angina symptoms and improving prognosis. However, some complications such as heart failure, adverse cardiac events, and even death cannot be avoided [21]. Furthermore, studies have shown that the anxiety and prevalence of depression in CHD patients will also increase, which will seriously affect the health-related quality of life [22]. Therefore, it is particularly important to develop an effective intervention to support patients with $\mathrm{CHD}$ in an appropriate approach of management of chronic diseases. Selfmanagement of chronic diseases is widely regarded as an effective way to support patients with chronic diseases to live the best possible quality of life [23-25]. Self-management is defined as "the individual's ability to manage the symptoms, treatment, physical and psychosocial consequences and lifestyle changes inherent in chronic diseases" [26]. Selfmanagement not only can help patients maintain health and related function but also can help patients solve and overcome problems.
We performed the PSOI and CSMS normality test on all data. The results of the PSOI and CSMS normality test showed that all data collected from total score or scores of each dimension did not obey the normal distribution. Thus, the Spearman method was used for correlation analysis. We discussed the statistical significance of the results and found that there was a negative correlation between the total score of PSOI and the total score of CSMS in Table 3. The value of coefficient was -0.142 . The patient which had a higher value of total score of PSOI had poorer sleep quality from the results of Table 3 .

\section{Discussion}

4.1. The Status of Sleep Quality in Hospitalized Elderly Patients with CHD. Studies have showed that sleep is the basic human physiological process. A good sleep quality can help relieve fatigue and stress, improve memory, promote the recovery of the vigor, and is more favorable for disease recovery [27, 28]. There were 120 volunteers in hospitalized elderly patients with CHD that participated in this study. Among them, 26 volunteers in hospitalized elderly patients with $\mathrm{CHD}$ had sleep disorders from the results of PSAI test and analysis. The rate of sleep disorder was $21.67 \%$. After analyzing and summarizing the data, we found that there were 120 hospitalized elderly CHD patients with a 
TABLE 2: Correlation analysis between sleep quality and cognitive function in patients with CHD.

\begin{tabular}{|c|c|c|c|c|c|c|c|c|c|c|c|}
\hline Variability & Statistics & $\begin{array}{c}\text { Visual } \\
\text { space and } \\
\text { executive } \\
\text { function }\end{array}$ & Name & Memory & Attention & Language & Abstract & $\begin{array}{l}\text { Delayed } \\
\text { memory }\end{array}$ & Orientation & $\begin{array}{l}\text { Additional } \\
\text { points }\end{array}$ & $\begin{array}{l}\text { Cognitive } \\
\text { total score }\end{array}$ \\
\hline \multirow{2}{*}{$\begin{array}{l}\text { Dimension } \\
1: \text { sleep } \\
\text { quality }\end{array}$} & $r$ & 0.060 & 0.009 & 0.033 & -0.044 & -0.075 & 0.041 & 0.098 & -0.119 & 0.063 & 0.057 \\
\hline & $P$ & 0.373 & 0.899 & 0.625 & 0.518 & 0.268 & 0.546 & 0.149 & 0.078 & 0.352 & 0.397 \\
\hline \multirow{2}{*}{$\begin{array}{l}\text { Dimension } \\
\text { 2: the time } \\
\text { to fall } \\
\text { asleep }\end{array}$} & $r$ & -0.006 & -0.010 & -0.021 & -0.007 & -0.084 & -0.042 & 0.034 & $-0.152^{*}$ & 0.081 & 0.009 \\
\hline & $P$ & 0.933 & 0.885 & 0.752 & 0.914 & 0.216 & 0.535 & 0.613 & 0.024 & 0.234 & 0.889 \\
\hline \multirow{2}{*}{$\begin{array}{l}\text { Dimension } \\
\text { 3: bedtime }\end{array}$} & $r$ & $-0.156^{*}$ & 0.008 & -0.076 & 0.024 & -0.019 & $-0.237^{* *}$ & -0.024 & $-0.272^{* *}$ & 0.055 & -0.042 \\
\hline & $P$ & 0.020 & 0.910 & 0.259 & 0.719 & 0.780 & $\leq 0.001$ & 0.727 & $\leq 0.001$ & 0.419 & 0.537 \\
\hline \multirow{2}{*}{$\begin{array}{l}\text { Dimension } \\
4: \text { sleep } \\
\text { efficiency }\end{array}$} & $r$ & -0.003 & -0.011 & 0.027 & 0.027 & 0.074 & $-0.205^{* *}$ & $-0.149^{*}$ & -0.131 & -0.087 & $\leq 0.001$ \\
\hline & $P$ & 0.962 & 0.875 & 0.686 & 0.686 & 0.273 & 0.002 & 0.027 & 0.052 & 0.200 & 0.998 \\
\hline \multirow{2}{*}{$\begin{array}{l}\text { Dimension } \\
\text { 5: sleep } \\
\text { disorders }\end{array}$} & $r$ & $-0.243^{* *}$ & $-0.244^{* *}$ & $-0.343^{* *}$ & $-0.288^{* *}$ & -0.078 & $-0.211^{* *}$ & $-0.298^{* *}$ & $-0.443^{* *}$ & 0.109 & $-0.349^{* *}$ \\
\hline & $P$ & $\leq 0.001$ & $\leq 0.001$ & $\leq 0.001$ & $\leq 0.001$ & 0.251 & 0.002 & $\leq 0.001$ & $\leq 0.001$ & 0.108 & $\leq 0.001$ \\
\hline \multirow{2}{*}{$\begin{array}{l}\text { Dimension } \\
\text { 6: sleep } \\
\text { medicine }\end{array}$} & $r$ & -0.057 & 0.001 & -0.117 & 0.036 & -0.044 & $-0.137^{*}$ & -0.072 & $-0.240^{* *}$ & -0.051 & -0.065 \\
\hline & $P$ & 0.397 & 0.991 & 0.085 & 0.590 & 0.512 & 0.043 & 0.287 & $\leq 0.001$ & 0.452 & 0.337 \\
\hline \multirow{2}{*}{$\begin{array}{l}\text { Dimension } \\
7 \text { : daytime } \\
\text { function }\end{array}$} & $r$ & $-0.227^{* *}$ & $-0.236^{* *}$ & $-0.211^{* *}$ & $-0.194^{* *}$ & $-0.180^{* *}$ & -0.065 & $-0.201^{* *}$ & $-0.327^{* *}$ & 0.100 & $-0.219^{* *}$ \\
\hline & $P$ & 0.001 & $\leq 0.001$ & 0.002 & 0.004 & 0.007 & 0.334 & 0.003 & $\leq 0.001$ & 0.138 & 0.001 \\
\hline \multirow{2}{*}{$\begin{array}{l}\text { Total scores } \\
\text { of sleep }\end{array}$} & $r$ & -0.081 & -0.082 & -0.097 & -0.072 & -0.093 & $-0.165^{*}$ & -0.084 & $-0.325^{* *}$ & 0.074 & -0.112 \\
\hline & $P$ & 0.232 & 0.225 & 0.153 & 0.291 & 0.167 & 0.014 & 0.216 & $\leq 0.001$ & 0.273 & 0.002 \\
\hline
\end{tabular}

Note: ${ }^{*} P<0.05,{ }^{* *} P<0.01$.

total PSQI score of $5.53 \pm 3.32$, which was higher than that of the normal score $(3.88 \pm 2.52)$ in China [29]. Therefore, the clinical staff should be highly concerned about the sleep quality of hospitalized elderly CHD patients.

4.2. Correlation between Sleep Quality and Cognitive Function in Patients with CHD. We analyzed the statistical data of Spearman, and the results showed that the correlation coefficient between the sleep quality score (PSQI total score) and the MoCA total score was negative, which means the patients with higher total score of sleep quality have worse cognitive ability. In addition, the patients with higher sleep quality score have worse sleep quality. In conclusion, the CHD patients with better sleep quality have better cognitive ability. Therefore, the sleep quality of hospitalized elderly CHD patients is positively correlated with cognitive ability. The correlation between sleep dimensions and cognitive ability dimensions in this study kept consistency with the results of Kang et al.'s study. Kang et al. [30] studied the correlation between cognitive ability and sleep status of 203 elderly patients ( $\geq 60$ years old) from Changsha city. They found that the Pittsburgh Sleep Quality Index (PSQI) has a negative correlation with attention, numeration ability, and language in six dimensions. Sleep maintenance disorders and daytime residual were all cardinal manifestations of sleep disorders. This may be related to less blood flow in the prefrontal cortex. In general, the prefrontal cortex is the main area that regulates cognitive activities like executive function and behavior. Sleep disorders impair cognitive ability by affecting the prefrontal cortex.

4.3. The Correlation between Sleep Quality and SelfManagement Ability of Patients with CHD. We analyzed the statistical data of Spearman, and the results showed that the correlation coefficient between the sleep quality score (PSQI total score) and the CSMS total score was negative, which means the patients with higher total score of sleep quality have the worse self-management ability. In addition, the patients with higher sleep quality score have worse sleep quality. In conclusion, the CHD patients with poor sleep quality have poorer self-management ability. Thus, the sleep quality of hospitalized elderly CHD patients is positively correlated with self-management ability. Disease selfmanagement refers to a healthy behavior that enhances patients' health through maintaining the patients' behavior, monitors and manages their physical and psychological symptoms, and reduces the impacts of diseases on social functions and emotions. In this study, the Pittsburgh Sleep 
TABLE 3: Correlation analysis between sleep quality and self-management in patients with CHD.

\begin{tabular}{|c|c|c|c|c|c|c|c|c|c|}
\hline Variability & Statistics & $\begin{array}{l}\text { Dimension 1: } \\
\text { bad } \\
\text { management } \\
\text { habits }\end{array}$ & $\begin{array}{l}\text { Dimension } \\
\text { 2: symptom } \\
\text { management }\end{array}$ & $\begin{array}{l}\text { Dimension 3: } \\
\text { emotional } \\
\text { and cognitive } \\
\text { management }\end{array}$ & $\begin{array}{c}\text { Dimension } \\
4: \\
\text { emergency } \\
\text { management }\end{array}$ & $\begin{array}{l}\text { Dimension } \\
\text { 5: disease } \\
\text { knowledge } \\
\text { management }\end{array}$ & $\begin{array}{l}\text { Dimension } \\
\text { 6: daily life } \\
\text { management }\end{array}$ & $\begin{array}{l}\text { Dimension } 7: \\
\text { treatment } \\
\text { compliance } \\
\text { and self- } \\
\text { management }\end{array}$ & $\begin{array}{l}\text { Total } \\
\text { scores } \\
\text { of } \\
\text { CSMS }\end{array}$ \\
\hline \multirow{2}{*}{$\begin{array}{l}\text { Dimension } \\
\text { 1: sleep } \\
\text { quality }\end{array}$} & $r$ & -0.010 & 0.037 & -0.021 & 0.051 & 0.058 & -0.103 & 0.068 & 0.024 \\
\hline & $P$ & 0.880 & 0.581 & 0.756 & 0.450 & 0.394 & 0.128 & 0.317 & 0.722 \\
\hline \multirow{2}{*}{$\begin{array}{l}\text { Dimension } \\
\text { 2: the time } \\
\text { to fall } \\
\text { asleep }\end{array}$} & $r$ & -0.129 & -0.046 & -0.074 & -0.022 & $-0.184^{* *}$ & $-0.205^{* *}$ & 0.011 & $-0.139^{*}$ \\
\hline & $P$ & 0.056 & 0.494 & 0.274 & 0.748 & 0.006 & 0.002 & 0.868 & 0.039 \\
\hline \multirow{2}{*}{$\begin{array}{l}\text { Dimension } \\
\text { 3: bedtime }\end{array}$} & $r$ & -0.014 & $0.139^{*}$ & -0.072 & $0.244^{* *}$ & 0.083 & -0.128 & 0.087 & 0.094 \\
\hline & $P$ & 0.840 & 0.039 & 0.288 & $\leq 0.001$ & 0.221 & 0.057 & 0.201 & 0.163 \\
\hline \multirow{2}{*}{$\begin{array}{l}\text { Dimension } \\
\text { 4: sleep } \\
\text { efficiency }\end{array}$} & $r$ & -0.120 & 0.126 & 0.067 & $0.345^{* *}$ & 0.032 & 0.046 & 0.115 & 0.124 \\
\hline & $P$ & 0.076 & 0.062 & 0.325 & $\leq 0.001$ & 0.637 & 0.502 & 0.089 & 0.065 \\
\hline \multirow{2}{*}{$\begin{array}{l}\text { Dimension } \\
\text { 5: sleep } \\
\text { disorders }\end{array}$} & $r$ & 0.109 & 0.066 & -0.002 & 0.088 & -0.013 & -0.112 & 0.080 & 0.040 \\
\hline & $P$ & 0.106 & 0.333 & 0.972 & 0.191 & 0.853 & 0.098 & 0.240 & 0.553 \\
\hline \multirow{2}{*}{$\begin{array}{l}\text { Dimension } \\
\text { 6: sleep } \\
\text { medicine }\end{array}$} & $r$ & 0.033 & 0.115 & $0.139^{*}$ & $0.185^{* *}$ & $0.184^{* *}$ & 0.033 & 0.096 & $0.208^{* *}$ \\
\hline & $P$ & 0.629 & 0.088 & 0.040 & 0.006 & 0.006 & 0.627 & 0.157 & 0.002 \\
\hline \multirow{2}{*}{$\begin{array}{l}\text { Dimension } \\
\text { 7: daytime } \\
\text { dysfunction }\end{array}$} & $r$ & 0.077 & -0.119 & -0.128 & -0.128 & $-0.139^{*}$ & $-0.305^{* *}$ & 0.032 & $-0.170^{*}$ \\
\hline & $P$ & 0.256 & 0.077 & 0.058 & 0.057 & 0.039 & $\leq 0.001$ & 0.633 & 0.011 \\
\hline \multirow{2}{*}{$\begin{array}{l}\text { Total } \\
\text { scores of } \\
\text { PSOI }\end{array}$} & $r$ & -0.050 & 0.060 & -0.031 & 0.101 & -0.054 & $-0.234^{* *}$ & 0.123 & -0.142 \\
\hline & $P$ & 0.458 & 0.378 & 0.652 & 0.134 & 0.424 & $\leq 0.001$ & 0.069 & 0.041 \\
\hline
\end{tabular}

Note: ${ }^{*} P<0.05,{ }^{* *} P<0.01$.

Quality Index (PSQI) was negatively related to disease knowledge management and daily life management in two dimensions. The self-management ability of $\mathrm{CHD}$ patients can be improved by maintaining a good quality sleep, staying awake during the daytime, and keeping a positive attitude.

\section{Conclusion}

By adopting questionnaire methods and statistical analysis, we investigated the status of sleep quality, cognitive function, and self-management ability of hospitalized elderly patients with coronary heart disease and discussed the correlation relationship among them. In investigating the total PSQI score of 120 hospitalized elderly CHD patients, there was a PSQI score of $5.53 \pm 3.32$. The Spearman analysis showed that the sleep quality of CHD patients was positively correlated with cognitive function and self-management ability. The sleep quality of elderly patients with coronary heart disease can be improved by improving the cognitive function, as well as their self-management ability. This research work provides a theoretical basis for improving the sleep quality of hospitalized elderly patients with coronary heart disease, improving cognitive function and self-management ability, and formulating personalized nursing plans.

\section{Data Availability}

The data used to support the findings of this study are available from the corresponding author upon request.

\section{Disclosure}

The funders had no role in the design of the study; in the collection, analyses, or interpretation of data; in the writing of the manuscript; or in the decision to publish the results.

\section{Conflicts of Interest}

The authors declare no conflict of interest.

\section{Authors' Contributions}

Zhoumin Shen and Huali Chen participated in the writing of this paper. Yimin Cai guided the writing of the paper and reviewed the manuscript. Zhou participated in the design and drafting of this manuscript. All authors have read and agreed to the published version of the manuscript. Zhoumin Shen and Huali Chen contributed equally to this work and should be considered co-first authors. 


\section{Acknowledgments}

This work was supported by Natural Science Foundation of Hunan Province (2018JJ2227).

\section{References}

[1] Writing Group Members, D. Mozaffarian, E. J. Benjamin et al., "Heart disease and stroke statistics-2016 update: a report from the American Heart Association," Circulation, vol. 133, no. 4, pp. e38-360, 2016.

[2] J. D. Schwalm, M. McKee, M. D. Huffman, and S. Yusuf, "Resource effective strategies to prevssent and treat cardiovascular disease," Circulation, vol. 133, no. 8, pp. 742-755, 2016.

[3] A. Liu, P. Kang, J. Liu, D. Li, and L. Zhang, "Effectiveness of comprehensive geriatric assessment in elderly patients with coronary heart disease," Biomedical Research, vol. 28, no. 17, 2017.

[4] G. Savarese and L. H. Lund, "Global public health burden of heart failure," Cardiac Failure Review, vol. 3, no. 1, p. 7, 2017.

[5] S. Zoungas, A. J. Curtis, J. J. McNeil, and A. M. Tonkin, "Treatment of dyslipidemia and cardiovascular outcomes: the journey so far-is this the end for statins?," Clinical Pharmacology and Therapeutics, vol. 96, no. 2, pp. 192-205, 2014.

[6] H. Haybar, M. Shokuhian, M. Bagheri, N. Davari, and N. Saki, "Involvement of circulating inflammatory factors in prognosis and risk of cardiovascular disease," Journal of Molecular and Cellular Cardiology, vol. 132, pp. 110-119, 2019.

[7] I. I. Abubakar, T. Tillmann, and A. Banerjee, "Global, regional, and national age-sex specific all-cause and cause-specific mortality for 240 causes of death, 1990-2013: a systematic analysis for the Global Burden of Disease Study 2013," Lancet, vol. 385, pp. 117-171, 2015.

[8] G. Kozdag, G. Ertas, E. Aygun et al., "Clinical effects of enhanced external counterpulsation treatment in patients with ischemic heart failure," Anadolu Kardiyoloji Dergisi, vol. 12, no. 3, pp. 214-221, 2012.

[9] H. Y. Ma, Z. P. Xing, R. L. Liu, S. H. Wang, and Y. L. Zhao, "Present situation and prospect of interventional therapy for coronary heart disease in China," Austin Cardiology, vol. 2, no. 1, p. 1010, 2017.

[10] M. Y. Ağargün, H. Kara, and O. Anlar, "Reliability and validity of Pittsburgh sleep quality index," Turkish Journal of Psychiatry, vol. 7, pp. 107-111, 1996.

[11] S. Schwartz, W. M. Anderson, S. R. Cole, J. Cornoni-Huntley, J. C. Hays, and D. Blazer, "Insomnia and heart disease: a review of epidemiologic studies," Journal of Psychosomatic Research, vol. 47, no. 4, pp. 313-333, 1999.

[12] D. A. Katz and C. A. McHorney, "Clinical correlates of insomnia in patients with chronic illness," Archives of Internal Medicine, vol. 158, no. 10, pp. 1099-1107, 1998.

[13] C. Leineweber, G. Kecklund, I. Janszky, T. Akerstedt, and K. Orth-Gomer, "Poor sleep increases the prospective risk for recurrent events in middle-aged women with coronary disease: the Stockholm Female Coronary Risk Study," Journal of Psychosomatic Research, vol. 54, no. 2, pp. 121-127, 2003.

[14] S. W. Schwartz, J. Cornoni-Huntley, S. R. Cole, J. C. Hays, D. G. Blazer, and D. D. Schocken, "Are sleep complaints an independent risk factor for myocardial infarction?," Annals of Epidemiology, vol. 8, no. 6, pp. 384-392, 1998.
[15] R. Asplund, "Sleep and cardiac diseases amongst elderly people," Journal of Internal Medicine, vol. 236, no. 1, pp. 65-71, 1994.

[16] N. T. Ayas, D. P. White, J. E. Manson et al., "A prospective study of sleep duration and coronary heart disease in women," Archives of Internal Medicine, vol. 163, no. 2, pp. 205-209, 2003.

[17] E. Jensen, O. Dehlin, B. Hagberg, G. Samuelsson, and T. Svensson, "Insomnia in an 80-year-old population: relationship to medical, psychological and social factors," Journal of Sleep Research, vol. 7, no. 3, pp. 183-189, 1998.

[18] V. S. Rains and T. F. Ditzler, "Sleep disorders and aging," The New England Journal of Medicine, vol. 326, no. 14, pp. 956957, 1992.

[19] N. Wolkove, O. Elkholy, M. Baltzan, and M. Palayew, "Sleep and aging: 1 . Sleep disorders commonly found in older people," CMAJ, vol. 176, no. 9, pp. 1299-1304, 2007.

[20] J. Niu, H. Han, Y. Wang, L. Wang, X. Gao, and S. Liao, “Sleep quality and cognitive decline in a community of older adults in Daqing City, China," Sleep Medicine, vol. 17, pp. 69-74, 2016.

[21] R. Itier and J. Roncalli, "New therapies for acute myocardial infarction: current state of research and future promise," Future Cardiology, vol. 14, no. 4, pp. 329-342, 2018.

[22] J. le, D. S. Dorstyn, E. Mpfou, E. Prior, and P. J. Tully, "Healthrelated quality of life in coronary heart disease: a systematic review and meta-analysis mapped against the International Classification of Functioning, Disability and Health," Quality of Life Research, vol. 27, no. 10, pp. 2491-2503, 2018.

[23] S. G. S. Gerward and D. S. D. Sahlin, "Self-care management intervention in heart failure," Turkish Journal of Psychiatry, vol. 21, pp. 525-525, 2019.

[24] K. Meng, G. Musekamp, M. Schuler et al., "The impact of a self-management patient education program for patients with chronic heart failure undergoing inpatient cardiac rehabilitation," Patient Education and Counseling, vol. 99, no. 7, pp. 1190-1197, 2016.

[25] L. P. Kimble, "A randomized clinical trial of the effect of an angina self-management intervention on health outcomes of patients with coronary heart disease," Rehabilitation Nursing, vol. 43, no. 5, pp. 275-284, 2018.

[26] N. H. Jonkman, M. J. Schuurmans, T. Jaarsma, L. M. Shortridge-Baggett, A. W. Hoes, and J. C. A. Trappenburg, "Selfmanagement interventions: proposal and validation of a new operational definition," Journal of Clinical Epidemiology, vol. 80, pp. 34-42, 2016.

[27] A. C. Guyton and J. E. Hall, Textbook of Medical Physiology, WB Saunders, Philadelphia, 11th ed edition, 2006.

[28] W. F. Ganong, Review of Medical Physiology, Connecticut McGraw-Hill, Stamford, 23th ed edition, 2009.

[29] X. Liu, M. Tang, and L. Hu, "Reliability and validity of the Pittsburgh sleep quality index," Chinese journal of psychiatry, vol. 29, pp. 103-107, 1996.

[30] J. X. Kang, H. Zeng, and P. Wang, "Correlation between sleep quality and cognitive functions of the elderly in community," Chinese General Practice, vol. 14, pp. 439-441, 2011. 